\title{
Endocrine complications of COVID-19: what happens to the thyroid and adrenal glands?
}

\author{
G. Bellastella ${ }^{1} \cdot$ M. I. Maiorino ${ }^{1} \cdot \mathrm{K}^{- \text {Esposito }^{2}}$
}

Received: 11 May 2020 / Accepted: 26 May 2020 / Published online: 1 June 2020

(C) Italian Society of Endocrinology (SIE) 2020

\section{Dear Editor,}

During the coronavirus disease 2019 (COVID-19) pandemic, several papers have reported the endocrine and metabolic conditions that may be considered risk factors for acquiring the new coronavirus (SARS-CoV-2) infection [1]. On the contrary, studies investigating whether SARS-CoV-2 may directly attack the endocrine glands, causing disorders that make the prognosis of affected patients worse are lacking.

Physicians know that several viruses may cause a subacute thyroiditis (de Quervain thyroiditis) and clusters of this disease have been reported during outbreaks of viral infection [2].

De Quervain thyroiditis is thought to have a viral origin, with possible pathogens including mumps virus, cytomegalovirus, enterovirus and Coxsackie virus [2]. Clinically, the condition is characterized by thyrotoxicosis with severe pain to the anterior aspect of the neck.

A possible localization of SARS-CoV-2 at the thyroid level cannot be excluded, considering that previous studies have demonstrated the presence of some virus-like particles in the follicular epithelium of patients with subacute thyroiditis [2]. Moreover, this gland is strictly contiguous to the structures of the superior airway, which are precociously invaded by this virus. Thyrotoxicosis may worsen the cardiovascular conditions, leading in some cases to tachyarrhythmia. To date, we know that some COVID-19 patients mention suffering from ear pain (which may be a symptom

G. Bellastella

giuseppe.bellastella@unicampania.it;

gbellastella@hotmail.com

1 Unit of Endocrinology and Metabolic Diseases, Department of Advanced Medical and Surgical Sciences, University of Campania '"Luigi Vanvitelli', Piazza L. Miraglia 2, 80138 Naples, Italy

2 Diabetes Unit, Department of Advanced Medical and Surgical Sciences, University of Campania "Luigi Vanvitelli',, 80138 Naples, Italy of subacute thyroiditis) and one of the most common cardiovascular complications of these patients is tachyarrhythmia. Therefore, a prompt evaluation of free thyroid hormones and TSH would allow early diagnosis and appropriate therapy, and help avoid more severe complications. Whereas subacute thyroiditis often occurs a few weeks after a viral infection of the upper respiratory tract and then it might be a late complication of SARS-CoV-2 infection, thyroid function should also be monitored during the follow-up of COVID19 patients.

Data published so far have not considered the possibility of direct aggression towards the adrenal gland by this virus in previously healthy subjects [3,4]. Viral, bacterial and fungal sepsis may cause haemorrhage, necrosis or thrombosis at the adrenal level with consequent acute hypoadrenalism. Moreover, recent findings have indicated the possibility of venous thrombo-embolism in COVID-19 patients and its favourable treatment by heparin in some of them (5). Thus, it has to be considered that an acute adrenal insufficiency may also be due to a thrombotic event at the adrenal level in COVID-19 patients. This could cause an acute adrenal insufficiency with impaired hormone production with consequent shock and worsening of the possibility of reacting to severe respiratory distress. A timely screening for pituitary-adrenal axis function and identification of this condition could allow adequate replacement therapy avoiding severe shock.

Histopathological findings and hormonal status of hospitalized COVID-19 patients should clarify these aspects. Finally, physicians are usually advised against the use of corticosteroid therapy in COVID-19 patients. However, in the presence of subacute thyroiditis or adrenal insufficiency, corticosteroid therapy should instead be mandatory for interrupting the release of high amounts of thyroid hormones, and to replace adrenal function, thus avoiding a dangerous worsening of clinical conditions of these patients. 


\section{Compliance with ethical standards}

Conflict of interest The authors declare that they have no conflict of interest.

Ethical approval This article does not contain any studies with human participants or animals performed by any of the authors.

Informed consent No informed consent.

\section{References}

1. Pal R, Banerjee M (2020) COVID-19 and the endocrine system: exploring the unexplored. J Endocrinol Invest. https://doi. org/10.1007/s40618-020-01276-8

2. Desaillud R, Hober D (2009) Virus and thyroiditis: an update. Virol J 6:5
3. Isidori AM, Arnaldi G, Boscaro M, Falorni A, Giordano C, Giordano R et al (2020) COVID-19 infection and glucocorticoids: update from the Italian Society of Endocrinology Expert Opinion on steroid replacement in adrenal insufficiency. J Endocrinol Invest. https://doi.org/10.1007/s40618-020-01266-w

4. Scaroni C, Armigliato M, Cannavò S (2020) COVID-19 outbreak and steroids administration: are patients treated for Sars-Cov-2 at risk of adrenal insufficiency? J Endocrinol Invest. https://doi. org/10.1007/s40618-020-01253-1

5. Porfidia A, Pola R, Porfidia A et al (2020) Venous thromboembolism in COVID-19 patients. J Throm Haemost. https://doi. org/10.1111//jth.14842

Publisher's Note Springer Nature remains neutral with regard to jurisdictional claims in published maps and institutional affiliations. 